\title{
Preparation of Thermo-Responsive and Cross-Linked Fluorinated Nanoparticles via RAFT-Mediated Aqueous Polymerization in Nanoreactors
}

\author{
Jiachen Ma 1,2, Luqing Zhang ${ }^{1,2}$, Bing Geng 1,2, Umair Azhar ${ }^{1,2}$, Anhou Xu 1,* \\ and Shuxiang Zhang ${ }^{1,2, *}$ \\ 1 Shandong Provincial Key Laboratory of Fluorine Chemistry and Chemical Materials, School of Chemistry \\ and Chemical Engineering, University of Jinan, Jinan 250022, China; majiachen9209@163.com (J.M.); \\ ujnb636@163.com (L.Z.); chm_gengb@ujn.edu.cn (B.G.); umair.azhar9922@gmail.com (U.A.) \\ 2 Shandong Engineering Research Center for Fluorinated Material, University of Jinan, Jinan 250022, China \\ * Correspondence: chm_xuah@ujn.edu.cn (A.X.); fhx_zhangsx@163.com (S.Z.); \\ Tel.: +86-151-6531-5109 (A.X.); +86-139-6912-9066 (S.Z.)
}

Academic Editor: Derek J. McPhee

Received: 23 September 2016; Accepted: 9 January 2017; Published: 25 January 2017

\begin{abstract}
In this work, a thermo-responsive and cross-linked fluoropolymer poly(2,2,2-Trifluoroethyl) methacrylate (PTFEMA) was successfully prepared by reversible addition-fragmentation chain transfer (RAFT) mediated aqueous polymerization with a thermo-responsive diblock poly(dimethylacrylamide$b$-N-isopropylacrylamide) (PDMA- $b$-PNIPAM) that performed a dual function as both a nanoreactor and macro-RAFT agent. The cross-linked polymer particles proved to be in a spherical-like structure of about $50 \mathrm{~nm}$ in diameter and with a relatively narrow particle size distribution. ${ }^{1} \mathrm{H}-\mathrm{NMR}$ and ${ }^{19} \mathrm{~F}-\mathrm{NMR}$ spectra showed that thermo-responsive diblock P(DMA- $b$-NIPAM) and cross-linked PTFEMA particles were successfully synthesized. Influence of the amount of ammonium persulfate (APS), the molar ratio of monomers to RAFT agent, influence of the amount of cross-linker on aqueous polymerization and thermo-responsive characterization of the particles are investigated. Monomer conversion increased from $44 \%$ to $94 \%$ with increasing the molar ratio of APS and P(DMA- $b$-NIPAM) from 1:9 to1:3. As the reaction proceeded, the particle size increased from 29 to $49 \mathrm{~nm}$ due to the consumption of TFEMA monomer. The size of cross-linked nanoparticles sharply decreased from 50.3 to 40.5 nm over the temperature range $14-44^{\circ} \mathrm{C}$, suggesting good temperature sensitivity for these nanoparticles.
\end{abstract}

Keywords: RAFT polymerization; nanoreactor; aqueous polymerization; cross-linking; temperature sensitivity

\section{Introduction}

In recent years, the study of fluoropolymers has gained tremendous attention because of their versatility. Excellent chemical resistance, thermal stability and other special properties enable them to be widely used in the fields of leather, textiles, building, and coating. In addition, many fluorinated polymers and small molecules have been widely used in medicine and drug delivery because of their biocompatibility and non-toxicity in vivo [1-3]. For example, sitagliptin, a selective, potent dipeptidyl peptidase IV DPP-4 inhibitor, is the active ingredient in JANUVIA ${ }^{\circledR}$ and JANUMET ${ }^{\circledR}$ (a fixed dose combination with the antidiabetic agent metformin), which both recently received approval for the treatment of type 2 diabetes by the FDA [4]. The most widely used method for the preparation of polymer nanoparticles is heterogeneous polymerization, including emulsion polymerization and dispersion polymerization. Aqueous polymerization is a relatively economical and versatile tool to produce nanoparticles with a low sensitivity to impurities [5]. Usually emulsifiers are used to stabilize such type of emulsions. These emulsifiers are very toxic and also need to be removed from 
the final product, which imparts extra costs. Based on the reasons above, emulsifier-free aqueous polymerization was developed. The main drawback of emulsifier-free aqueous polymerization was the broad particle size distribution (PSD) with little or no control over particle size.

With the development of controlled/living radical polymerization (CLRP) the problem of large dispersity $(Đ)$ and uncontrolled molecular weight has been overcome to a large extent [6]. Researchers simultaneously found that it is a good way to produce particles with narrow size distribution. CLRP include nitroxide-mediated polymerization, atom transfer radical polymerization and reversible addition-fragmentation chain transfer (RAFT) polymerization [7-9]. Among these methods, RAFT polymerization has distinct advantages compared to others. It can be applied to synthesize polymers or copolymers with narrow molecular weight distribution for most monomers amenable to radical polymerization. The molecular weight of the final product can be predicted from the ratio of monomer consumed to chain transfer agent. In addition, there is compatibility with a vast range of functional monomers, solvents and initiators. Also, there is no undesired metal species introduced during the RAFT polymerization process $[9,10]$.

Considerable attention has been directed towards the synthesis of polymer nanoparticles via RAFT polymerization in dispersed aqueous medium (e.g., emulsion, miniemulsion) due to its capability of controlled molecular weight and dispersity [6,11-16]. Firstly, homopolymers and copolymers are synthesized and then used in aqueous RAFT polymerization. During this process amphiphilic block copolymers not only provide an ideal setting for polymerization to prevent the aggregation of nanoparticles but also acts as a reactant to produce products with well-controlled dispersity [6]. Many organic reactions have been carried out in nanoreactors $[17,18]$. These nanoreactors can provide a nano-sized space for the reaction to take place. For P(DMA-b-NIPAM) copolymer, the PNIPAM block is hydrophilic and water-soluble below its lower critical solution temperature (LCST $~ 36^{\circ} \mathrm{C}$ ) [19] while above its LCST it forms self-stabilized monodisperse nanoreactors [6]. The main advantages of carrying out CLRP using nanoreactors are the following: (1) easy to form micelles in water with better emulsion stability; (2) pure products can be obtained with low dispersity and no residual emulsifier [20-23].

In this study, thermo-responsive and cross-linked poly((2,2,2-trifluoroethyl)methacrylate) nanoparticles were successfully prepared. Firstly, a thermo-responsive diblock copolymer based on RAFT solution polymerization was synthesized. The diblock copolymer containing a RAFT end group is used for RAFT-mediated aqueous polymerization to prepare cross-linked nanospheres due to its self-emulsifying property. Homopolymer PNIPAM has been extensively studied for drug delivery applications because of its lower critical solution temperature (LCST) (at $\sim 32{ }^{\circ} \mathrm{C}$ ) [24]. However, PNIPAM homopolymers suffer from syneresis and lack of biodegradability. The fluorinated core-shell structure can retain temperature-sensitive properties and water absorption along with the uniformity and stability of nanospheres. The strong hydrophobicity of the fluorinated core can enhance the performance of the loading of hydrophobic drug. To our knowledge, this is the first time to synthesize thermo-responsive fluoropolymer nanospheres. It may have an attractive application prospect in drug controlled release.

\section{Results and Discussion}

\subsection{Synthesis and Characterization of PDMA-S- $(C=S)-S-C_{12} H_{25}$ and $P(D M A-b-N I P A M)-S-(C=S)-S-C_{12} H_{25}$}

$\mathrm{P}$ (DMA- $b$-NIPAM)-S-(C=S)-S- $\mathrm{C}_{12} \mathrm{H}_{25}$ was synthesized via a two-step RAFT solution polymerization of dimethylacrylamide (DMA) and $\mathrm{N}$-isopropylacrylamide (NIPAM) with the trithiocarbonate RAFT agent 2-([(dodecylsulfanyl)carbonothioyl]sulfanyl)propanoic acid. As the ${ }^{1} \mathrm{H}-\mathrm{NMR}$ spectra in Figure 1 shows, all proton signals are assigned. In Figure $1 \mathrm{~B}$, the feature signals of the polydimethylacrylamide (PDMA) segment are seen (1.42-1.91 ppm - $\mathrm{CH}_{2}$ - backbone PDMA; 2.30-2.78 ppm - $\mathrm{CH}$ - backbone PDMA; 2.78-3.27 ppm dimethyl group of $\mathrm{NMe}_{2}$, PDMA) [25]. For the diblock ${ }^{1} \mathrm{H}-\mathrm{NMR}$ spectrum in Figure 1C, the feature signals of PDMA still remain, while the feature signals of poly( $N$-isopropylacrylamide) (PNIPAM) now appear (3.80-4.22 ppm-CH- in side chain PNIPAM; 6.67-7.75 ppm -NH-, PNIPAM) [6,25]. 
The signal at $0.95 \mathrm{ppm}$ is attributed to the methyl protons of the RAFT agent, which indicates that the structure of the final polymer still keeps the functional group of the RAFT agent. The chemical structure of the chain transfer agent (CTA), macro-RAFT agent and diblock are thus confirmed from the ${ }^{1} \mathrm{H}-\mathrm{NMR}$.

(A)
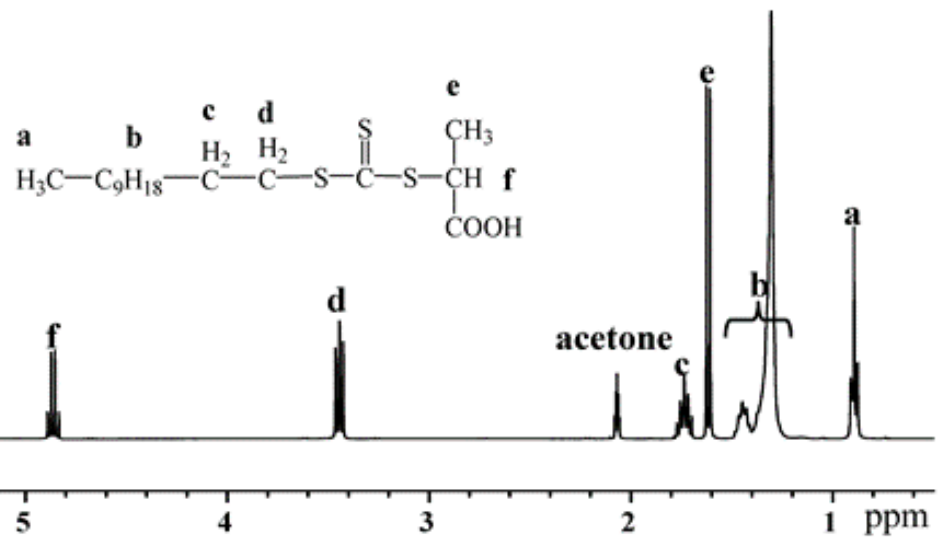

(B)

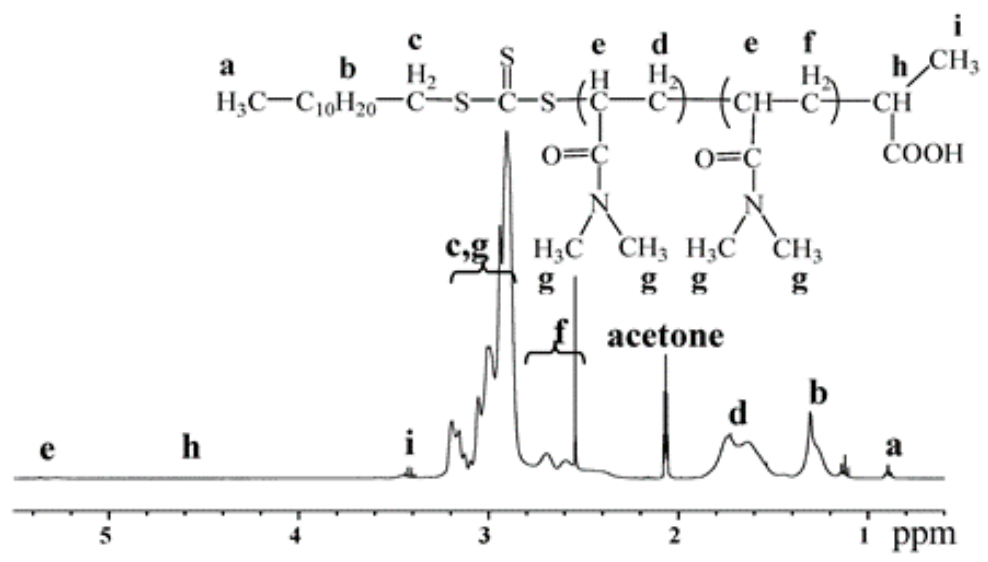

(C)

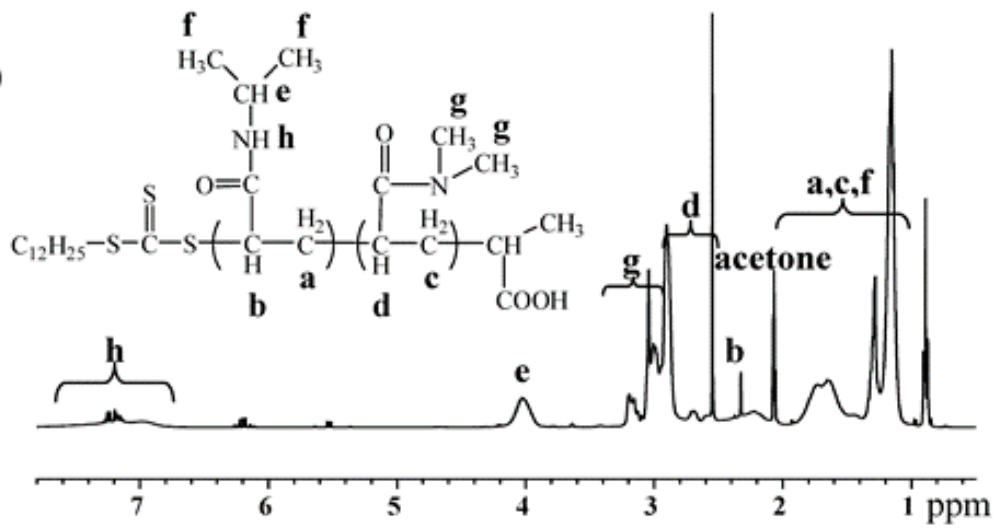

Figure 1. ${ }^{1} \mathrm{H}-\mathrm{NMR}$ spectra of $(\mathbf{A}) \mathrm{HOOCCH}\left(\mathrm{CH}_{3}\right)-\mathrm{S}-(\mathrm{C}=\mathrm{S})-\mathrm{S}-\mathrm{C}_{12} \mathrm{H}_{25} ;$ (B) macro-CTA PDMA $73-\mathrm{S}-(\mathrm{C}=\mathrm{S})$ S- $\mathrm{C}_{12} \mathrm{H}_{25} ;(\mathbf{C})$ copolymer $\mathrm{P}\left(\mathrm{DMA}_{73}-b\right.$-NIPAM 77$)-\mathrm{S}-(\mathrm{C}=\mathrm{S})-\mathrm{S}-\mathrm{C}_{12} \mathrm{H}_{25}$ in acetone.

Tables 1 and 2 show the data of the synthesis of poly( $N, N$-dimethylacrylamide) (PDMA) and PDMA- $b$-PNIPAM. Figure 2A shows the gel permeation chromatography (GPC) traces of the macroRAFT agent of PDMA-S-(C=S)-S- $\mathrm{C}_{12} \mathrm{H}_{25}$ with a different ratio of monomer and RAFT agent, resulting in a different degree of polymerization. Based on the GPC traces eluted by THF, the different molecular weights ranging from 3900 to $10,800 \mathrm{~g} / \mathrm{mol}$ with low dispersity (<1.1) for PDMA-S-(C=S)-S-C ${ }_{12} \mathrm{H}_{25}$ are 
obtained. Figure 2B shows the GPC traces of P(DMA-b-NIPAM)-S-(C=S)-S- $\mathrm{C}_{12} \mathrm{H}_{25}$ synthesized by the same macro-RAFT agent. Diblock copolymers ranging from 7200 to $22,000 \mathrm{~g} / \mathrm{mol}$ with low dispersity were successfully obtained. These results confirm the well-controlled RAFT polymerization.

Table 1. Data for the reversible addition-fragmentation chain transfer (RAFT) mediated polymerization of $N, N$-dimethylacrylamide (DMA) at $65^{\circ} \mathrm{C}$ in dioxane.

\begin{tabular}{cccccc}
\hline [DMA]:[DOPAT] & $\mathbf{M}_{\mathbf{n}, \text { target }^{\mathbf{a}}}{ }^{\mathbf{( g / m o l})}$ & $\mathbf{x}^{\mathbf{b}} \mathbf{( \% )}$ & $\mathbf{M}_{\mathbf{n}, \text { theory }}{ }^{\mathbf{c}}(\mathbf{g} / \mathbf{m o l})$ & $\mathbf{M}_{\mathbf{n}, \mathbf{G P C}}{ }^{\mathbf{d}}$ & $\mathbf{\Xi}^{\mathbf{e}}$ \\
\hline $35: 1$ & 3800 & 97 & 3700 & 3900 & 1.09 \\
$100: 1$ & 10,250 & 84 & 8700 & 7500 & 1.11 \\
$150: 1$ & 15,200 & 73 & 11,200 & 10,700 & 1.09 \\
\hline
\end{tabular}

a target molecular weight $\left(\mathrm{M}_{\mathrm{n}}\right)$ of PDMA; ${ }^{\mathrm{b}}$ conversion of DMA calculated by gravimetry; ${ }^{\mathrm{c}}$ calculated from the equation: $\mathrm{M}_{\mathrm{n} \text {,theory }}=\frac{[\mathrm{DMA}]}{[\text { DOPAT }]} \times \mathrm{M}_{\mathrm{DMA}} \times$ conversion $+\mathrm{M}_{\text {DOPAT }}$ where $\mathrm{M}_{\text {DOPAT }}$ is the molecular weight of 2-([(dodecylsulfanyl)carbonothioyl]sulfanyl)-propanoic acid (DOPAT); ${ }^{\mathrm{d}} \mathrm{THF}$ was used as eluent at a flow rate of $1.0 \mathrm{~mL} / \mathrm{min}^{\text {e }}$ dispersity of PDMA.

Table 2. Data for the RAFT-mediated polymerization of $\mathrm{N}$-isopropylacrylamide (NIPAM) at $65^{\circ} \mathrm{C}$ in dioxane.

\begin{tabular}{cccccc}
\hline [NIPAM]:[macro-CTA] & $\mathbf{M}_{\mathbf{n}, \text { target }}{ }^{\mathbf{a}} \mathbf{( g / m o l )}$ & $\mathbf{x}^{\mathbf{b}} \mathbf{( \% )}$ & $\mathbf{M}_{\mathbf{n}, \text { theory }}{ }^{\mathbf{c}}(\mathbf{g} / \mathbf{m o l})$ & $\mathbf{M}_{\mathbf{n}, \mathrm{GPC}} \mathbf{d}^{\mathbf{\Xi}^{\mathbf{e}}}$ \\
\hline $40: 1$ & 8100 & 92 & 7700 & 7200 & 1.07 \\
$100: 1$ & 17,200 & 78 & 12,400 & 14,800 & 1.16 \\
$250: 1$ & 31,800 & 64 & 20,300 & 22,000 & 1.17 \\
\hline
\end{tabular}

${ }^{a}$ target molecular weight $\left(\mathrm{M}_{\mathrm{n}}\right)$ of PDMA- $b$-PNIPAM; ${ }^{\mathrm{b}}$ conversion of NIPAM calculated by gravimetry;

${ }^{c}$ calculated from the equation: $\mathrm{M}_{n, \text { theory }}=\frac{[\mathrm{NIPAM}]}{[\text { macro-CTA }]} \times \mathrm{M}_{\mathrm{NIPAM}} \times$ conversion $+\mathrm{M}_{\mathrm{n}, \mathrm{PDMA}}$ where $\mathrm{M}_{\mathrm{n}, \mathrm{PDMA}}$ is the molecular weight of the $\mathrm{PDMA}_{33}$ macro-CTA; ${ }^{\mathrm{d}}$ THF was used as eluent at a flow rate of $1.0 \mathrm{~mL} / \mathrm{min}$; e dispersity of PDMA- $b$-PNIPAM.

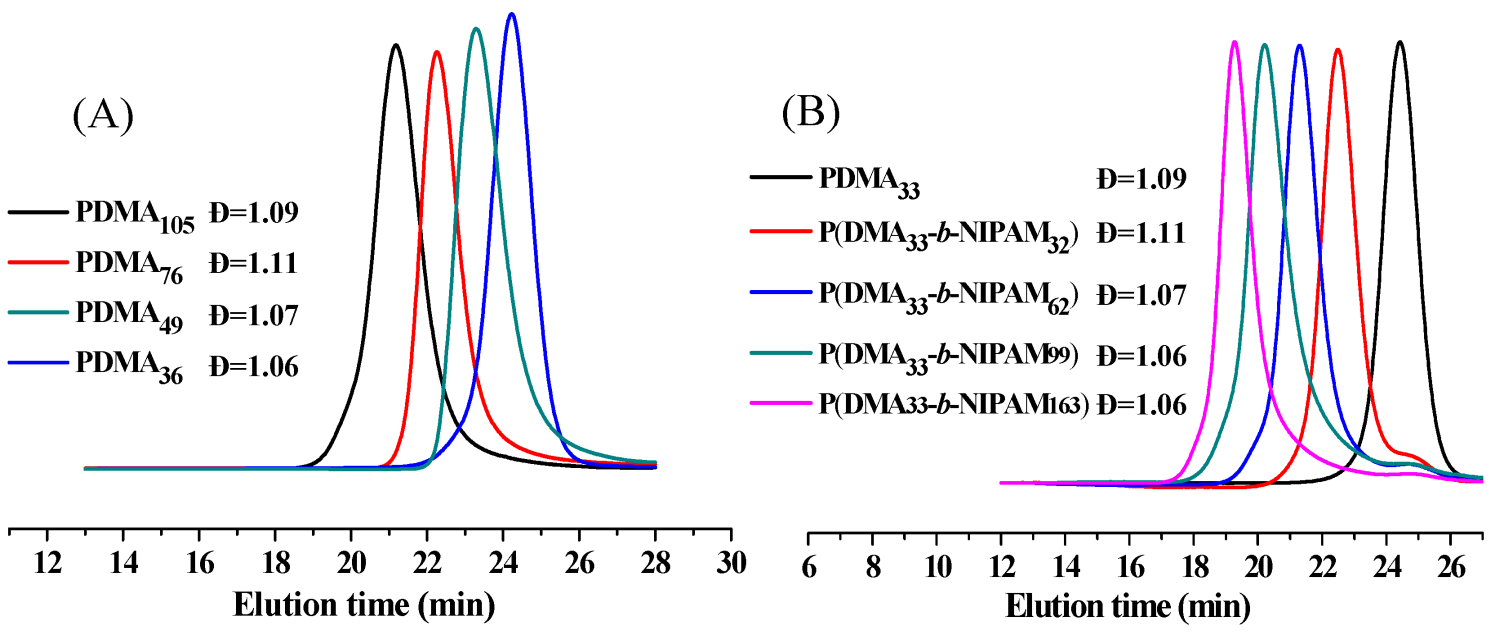

Figure 2. Gel permeation chromatography (GPC) traces of homopolymer or diblock copolymer eluted by THF. (A) macro-RAFT agent of PDMA-S-(C=S)-S- $\mathrm{C}_{12} \mathrm{H}_{25}$ with different degree of polymerization; (B) P(DMA- $b$-NIPAM)-S-(C=S)-S- $\mathrm{C}_{12} \mathrm{H}_{25}$ copolymers prepared with the molar ratios of NIPAM/PDMA $33-\mathrm{S}-(\mathrm{C}=\mathrm{S})-\mathrm{S}-\mathrm{C}_{12} \mathrm{H}_{25}$ at 43:1, 80:1, 140:1 and 250:1. Polymerization conditions: $\mathrm{PDMA}_{33}-\mathrm{S}-(\mathrm{C}=\mathrm{S})-\mathrm{S}-\mathrm{C}_{12} \mathrm{H}_{25}:[\mathrm{AIBN}]=7: 1,65^{\circ} \mathrm{C}, 20 \mathrm{~h}$. 


\subsection{Crosslinking Polymerization of TFEMA in Nanoreactors Formed} by $P(D M A-b-N I P A M)-S-(C=S)-S-C_{12} H_{25}$

Thermo-responsive block polymers have been extensively studied for drug delivery and extraction. Gupta's group reported that thermo-responsive triblock polymer poly-[(propylenesulfide)$b$-(N,N-dimethylacrylamide)- $b$-( $N$-isopropylacrylamide)] (PPS- $b$-PDMA- $b$-PNIPAAM) can form micelles at room temperature $\left(25^{\circ} \mathrm{C}\right)$. The micelles preloaded with the model drug Nile Red will form hydrogels upon heating to physiologic temperature $\left(37^{\circ} \mathrm{C}\right)$, and the resulting hydrogels demonstrated reactive oxygen species (ROS)- dependent drug release [26]. Duhamel et al. demonstrated that poly(ethylene glycol)-b-poly(2-(2-methoxyethoxy) ethyl methacrylate) (PEG-b-PMEO $2 \mathrm{MA}$ ) has the ability to extract oil from oil sands [27].

Optical photographs of the thermo-responsive block polymers that we synthesized are shown in Figure 3; the solution was transparent at $25{ }^{\circ} \mathrm{C}$. When the temperature was raised to $40{ }^{\circ} \mathrm{C}$, the $\mathrm{P}\left(\mathrm{DMA}_{33}-b\right.$-NIPAM $)-\mathrm{S}-(\mathrm{C}=\mathrm{S})-\mathrm{S}-\mathrm{C}_{12} \mathrm{H}_{25}(\mathrm{x}=63,130,163)$ solution became opaque, while $\mathrm{P}\left(\mathrm{DMA}_{33}-b-\mathrm{NIPAM}{ }_{32}\right)-\mathrm{S}-(\mathrm{C}=\mathrm{S})-\mathrm{S}-\mathrm{C}_{12} \mathrm{H}_{25}$ showed no change. The thermo-responsive diblock $\mathrm{P}\left(\mathrm{DMA}-b\right.$-NIPAM)-S-(C=S)-S- $\mathrm{C}_{12} \mathrm{H}_{25}$ can completely dissolve in water below the LCST of the PNIPAM block. The behavior of the PNIPAM block changes from soluble into insoluble once the temperature is above the LCST, resulting in the aggregation of PNIPAM segments to form nanoreactors, and hydrophilic segment PDMA acts as a stabilizer for the nanoreactors. The nanoreactors can encapsulate TFEMA monomers and cross-linker EGDMA for reaction. Intensity weighted distributions of the hydrodynamic diameter were obtained by dynamic light scattering (DLS). The micelle hydrodynamic diameter increased from 16 to $33 \mathrm{~nm}$ while the degree of polymerization of the PNIPAM segment increased from 63 to 163 . The PNIPAM segments of P(DMA $\left.{ }_{33}-b-\mathrm{NIPAM}_{32}\right)-\mathrm{S}-(\mathrm{C}=\mathrm{S})-\mathrm{S}-\mathrm{C}_{12} \mathrm{H}_{25}$ are too short to stabilize the micelles.
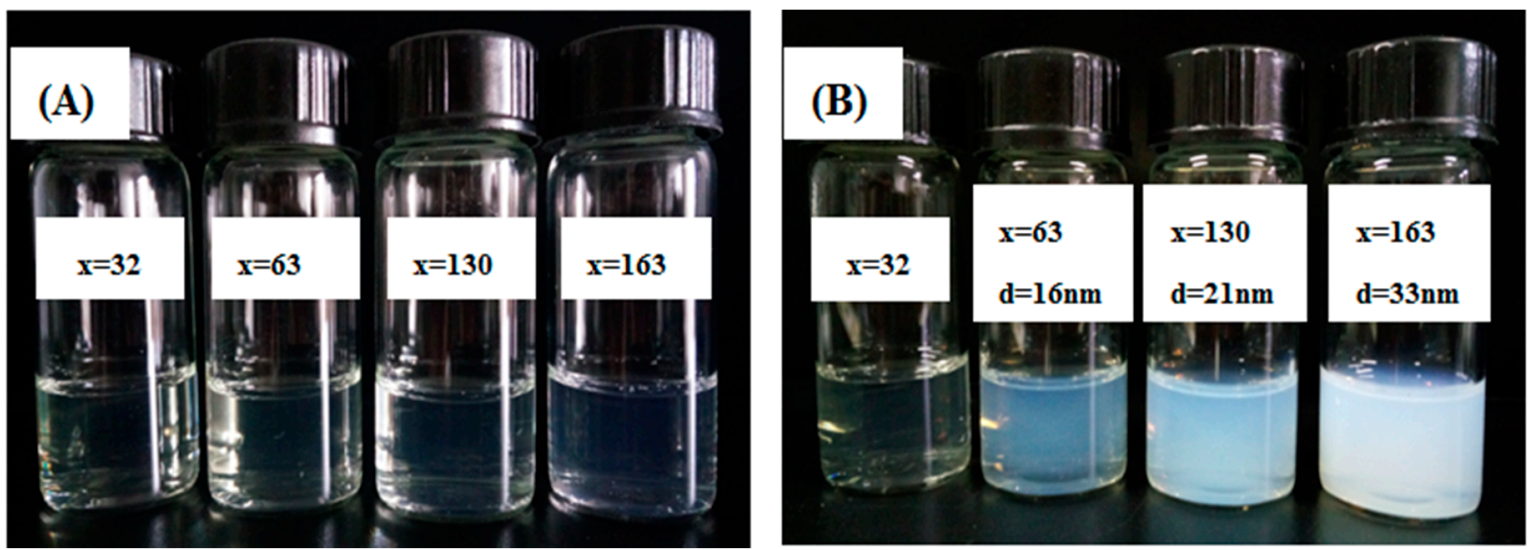

Figure 3. (A) Optical photographs of $\mathrm{P}\left(\mathrm{DMA}_{33}-b-\mathrm{NIPAM}_{\mathrm{x}}\right)-\mathrm{S}-(\mathrm{C}=\mathrm{S})-\mathrm{S}-\mathrm{C}_{12} \mathrm{H}_{25}(\mathrm{x}=32,63,130,163)$ aqueous solution with $2.0 \mathrm{wt} \%$ concentration at $25^{\circ} \mathrm{C}$; (B) Optical photographs at $40{ }^{\circ} \mathrm{C}$ and diameter measured by dynamic light scattering (DLS).

The aqueous solution containing P(DMA- $b$-NIPAM)-S-(C=S)-S- $\mathrm{C}_{12} \mathrm{H}_{25}$, APS, TFEMA and EGDMA will undergo polymerization in nanoreactors to generate cross-linked nanoparticles. Figure 4 shows the ${ }^{19}$ F-NMR spectrum of lyophilized triblock copolymer P(DMA D $_{33}-b-N_{\text {NIPAM }} 163-b$ TFEMA $\left._{50}\right)-\mathrm{S}-(\mathrm{C}=\mathrm{S})-\mathrm{S}-\mathrm{C}_{12} \mathrm{H}_{25}$. The characteristic signals of the PTFEMA segment ( $-73.8 \mathrm{ppm}-\mathrm{CF}_{3}$ in side chain PTFEMA) can be seen. The particle morphology, shown by the transmission electron microscopy (TEM) and scanning electron microscopy (SEM) images in Figures 5 and 6, clearly suggests that stable and monodisperse spherical nanoparticles were formed. The particles' corona was formed by P(DMA- $b$-NIPAM) and the cross-linked PTFEMA block forms the hydrophobic core. 


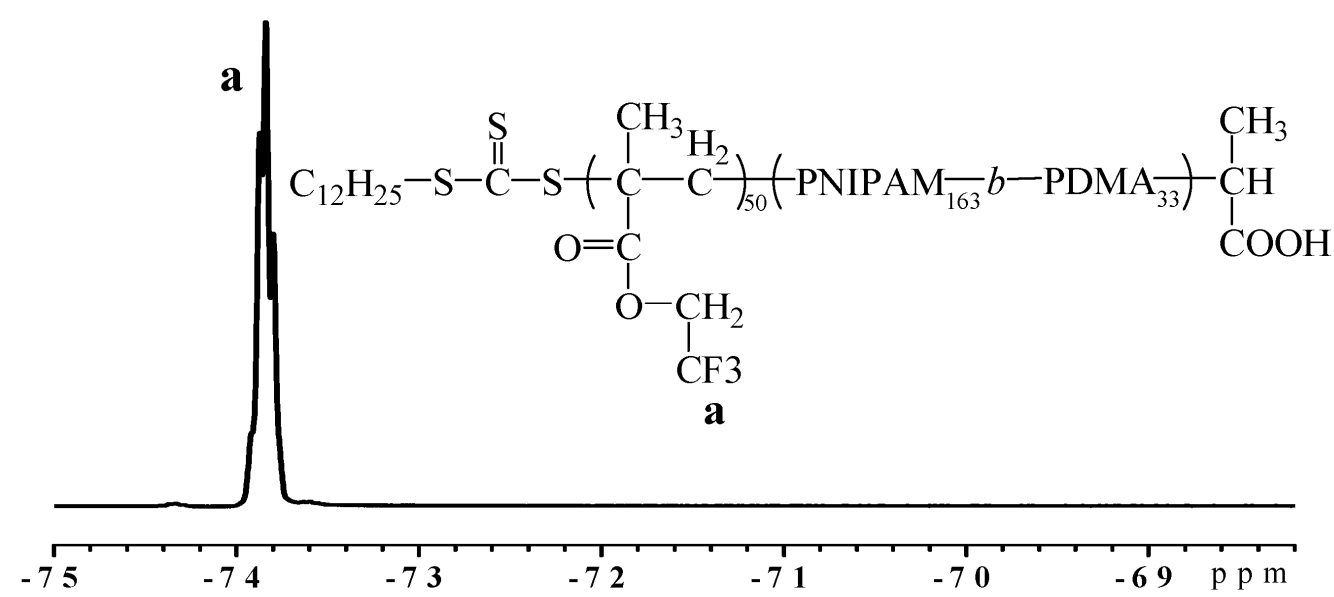

Figure 4. ${ }^{19} \mathrm{~F}-\mathrm{NMR}$ spectrum of $\mathrm{P}\left(\mathrm{DMA}_{33}-b-\mathrm{NIPAM} \mathrm{M}_{163}-b-\mathrm{TFEMA}_{50}\right)-\mathrm{S}-(\mathrm{C}=\mathrm{S})-\mathrm{S}-\mathrm{C}_{12} \mathrm{H}_{25}$ nanoparticles.

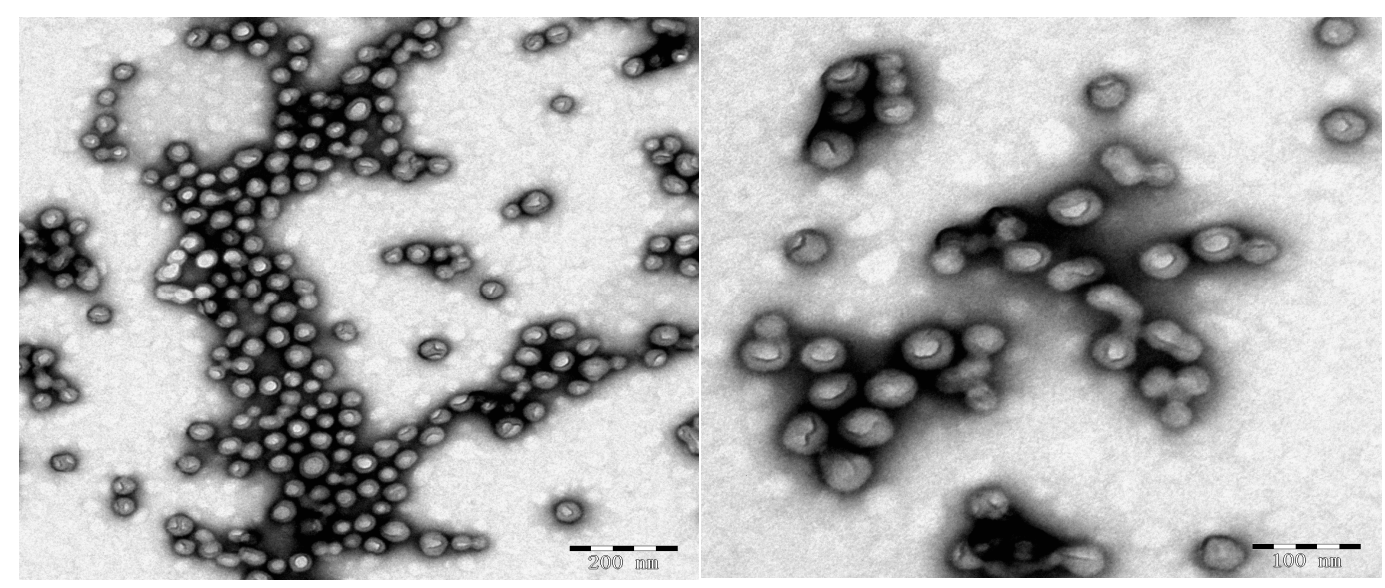

Figure 5. Transmission electron microscopy (TEM) images for the final latex of RAFT-mediated aqueous polymerization of TFEMA in the presence of P(DMA- $b$-NIPAM)-S-(C=S)-S- $\mathrm{C}_{12} \mathrm{H}_{25}$. Polymerization conditions: $\left.\mathrm{P}_{\left(\mathrm{DMA}_{46}-b-\mathrm{NIPAM}_{31}\right)-\mathrm{S}-(\mathrm{C}=\mathrm{S})-\mathrm{S}-\mathrm{C}_{12} \mathrm{H}_{25} \text { :[APS] }=3: 1, \mathrm{P}\left(\mathrm{DMA}_{46}-b \text {-NIPAM }\right.}^{31}\right)-\mathrm{S}-(\mathrm{C}=\mathrm{S})-\mathrm{S}-$ $\mathrm{C}_{12} \mathrm{H}_{25}:\left[\right.$ TFEMA] $=1: 200,\left[\right.$ EGDMA]:[TFEMA] $=5: 100,70{ }^{\circ} \mathrm{C}, 120 \mathrm{~min}$.

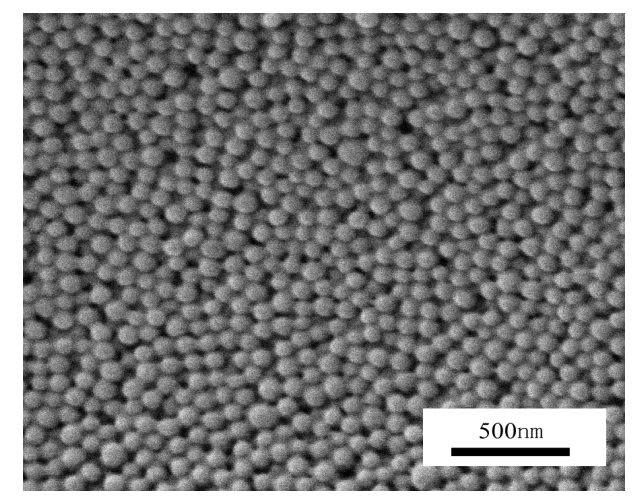

Figure 6. Scanning electron microscopy (SEM) image for the lyophilized triblock copolymer $\mathrm{P}\left(\mathrm{DMA}_{33^{-}}\right.$ $b$-NIPAM ${ }_{32}-b$-TFEMA 500$)$-S- $(\mathrm{C}=\mathrm{S})-\mathrm{S}-\mathrm{C}_{12} \mathrm{H}_{25}$. Polymerization conditions: $\mathrm{P}\left(\mathrm{DMA}_{33}-b\right.$-NIPAM 32$)-\mathrm{S}-$ $(\mathrm{C}=\mathrm{S})-\mathrm{S}-\mathrm{C}_{12} \mathrm{H}_{25}$ :[APS] = 3:1, P(DMA $\left.{ }_{33}-b-\mathrm{NIPAM}_{32}\right)-\mathrm{S}-(\mathrm{C}=\mathrm{S})-\mathrm{S}-\mathrm{C}_{12} \mathrm{H}_{25}$ :[TFEMA] = 1:500, [EGDMA]: $\left[\right.$ TFEMA] $=5: 100,70{ }^{\circ} \mathrm{C}, 120 \mathrm{~min}$. 


\subsection{Influence of the Amount of APS on Aqueous Polymerization}

Several sets of experiments using different amounts of APS were carried out. Samples were withdrawn at regular time intervals for determination of monomer conversion and particle size. The particle size and the distribution of highly diluted samples were measured by DLS. Figure 7 shows the evolution of TFEMA conversion versus time for RAFT-mediated aqueous polymerization using $\mathrm{P}\left(\mathrm{DMA}_{77}-b\right.$-NIPAM 73$)-\mathrm{S}-(\mathrm{C}=\mathrm{S})-\mathrm{S}-\mathrm{C}_{12} \mathrm{H}_{25}$ as macro-RAFT agent.
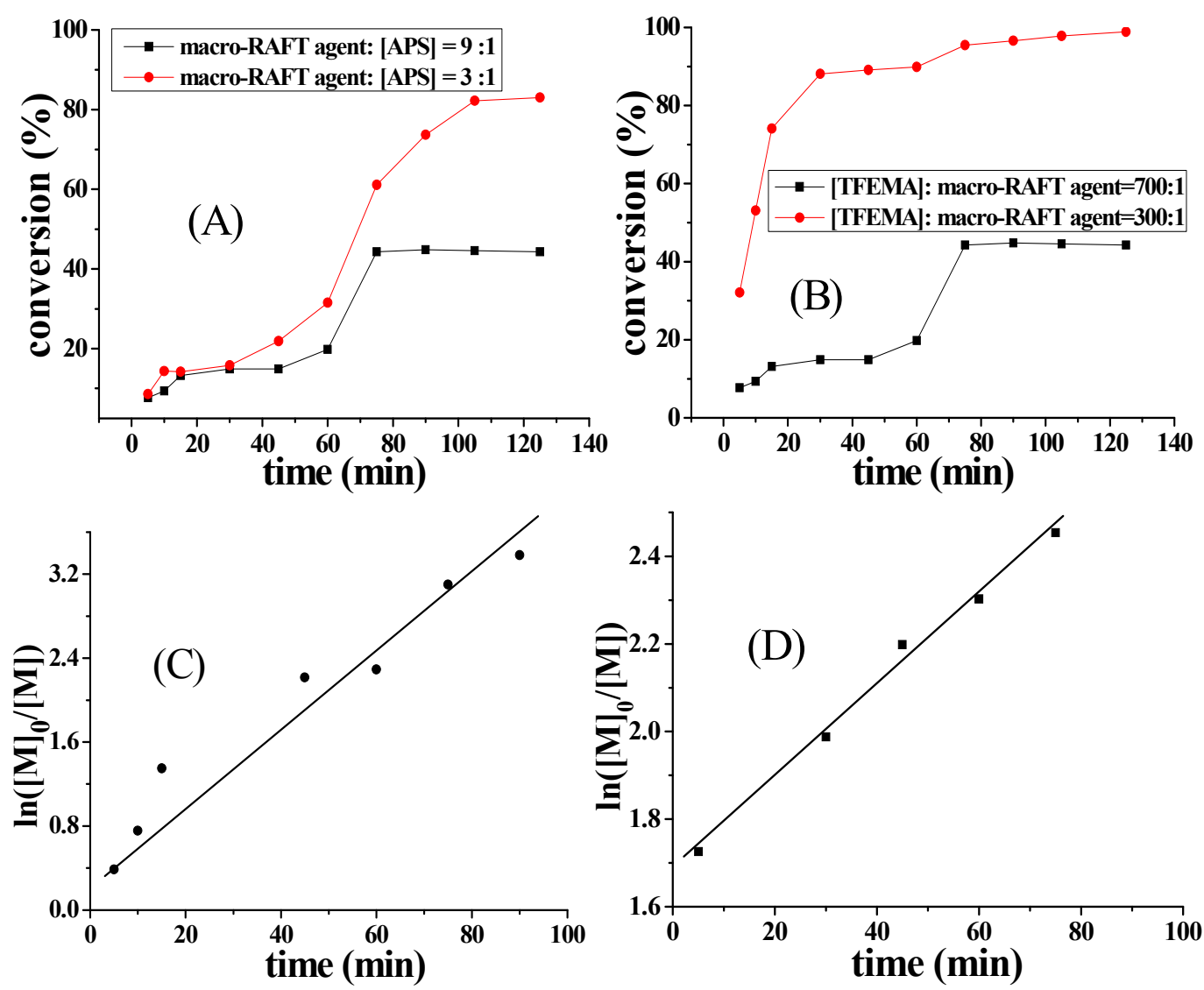

Figure 7. Evolutions of TFEMA conversion versus time for RAFT-mediated aqueous polymerization. Polymerization conditions: (A) macro-RAFT agent:[TFEMA] = 1:700, [EGDMA]:[TFEMA] = 5:100, $70{ }^{\circ} \mathrm{C}$; (B) macro-RAFT agent:[APS] = 3:1, [EGDMA]:[TFEMA] = 5:100, $70{ }^{\circ} \mathrm{C}$; (C) macro-RAFT agent:[TFEMA] = 1:300, macro-RAFT agent:[APS] = 3:1 [EGDMA]:[TFEMA] $=5: 100,70{ }^{\circ} \mathrm{C} ;($ D) macro-RAFT agent:[TFEMA] $=1: 300$, macro-RAFT agent:[APS] $=9: 1,[$ EGDMA]:[TFEMA $]=5: 100,70{ }^{\circ} \mathrm{C}$.

As shown in Figure 7A the final monomer conversion was $44.3 \%$ when the molar ratio of APS and chain transfer agent was 1:9. The final monomer conversion reached $94.2 \%$ upon changing the molar ratio of APS and chain transfer agent from 1:9 to 1:3. The low APS concentration process could not generate enough radicals to initiate the reaction, resulting in low monomer conversion. By increasing the amount of APS, the polymerization rate increased due to the increase of the number of radicals. Figure 7B shows the evolution of TFEMA conversion versus time, keeping the same amount of initiator. In the two experiments, the molar ratio of TFEMA and macro-RAFT agent was varied, but the amount of initiator was held constant. In the later stages of the reaction, there was not enough initiator to initiate the reaction. As a result, the conversion of the reaction with more monomer was low [28]. 


\subsection{Influence of Amount of Cross-Linker on Nanoparticles}

Several experiments were conducted with adding different amounts of cross-linker EGDMA. During this process, $\mathrm{P}\left(\mathrm{DMA}_{46}-b-\mathrm{NIPAM}_{31}\right)-\mathrm{S}-(\mathrm{C}=\mathrm{S})-\mathrm{S}-\mathrm{C}_{12} \mathrm{H}_{25}$ was used as macro-RAFT agent. From the results we can conclude that the amount of the EGDMA has a significant influence on particle size. As shown in Figure 8, particle size increased linearly with increasing amount of EGDMA. This is because the increase of amount of cross-linker leads to high cross-linking density. As a result, the number of block copolymers connected on each nanoreactor is also increased, leading to larger particle size.

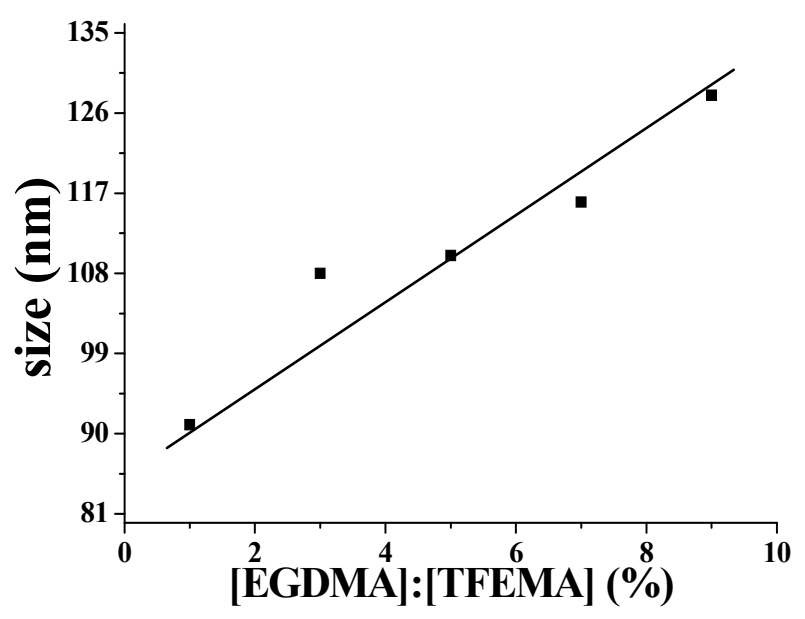

Figure 8. Relationship between particle size and amount of EGDMA added during RAFT-mediated polymerization. Polymerization conditions: macro-RAFT agent:[TFEMA] = 1:700, macro-RAFT agent:[APS] $=3: 1,70{ }^{\circ} \mathrm{C}, 120 \mathrm{~min}$.

\subsection{Influence of Amount of TFEMA on the Nanoparticles}

The effect of amount of TFEMA on particle size was investigated using P(DMA $\left.46-b-\mathrm{NIPAM}_{31}\right)-\mathrm{S}-$ (C=S)-S- $\mathrm{C}_{12} \mathrm{H}_{25}$ as macro-RAFT agent. Intensity weighted distributions of the hydrodynamic diameter were obtained by DLS. Figure 9 shows the evolution of particle size versus time or TFEMA conversion. As the reaction proceeded, the particle size in diameter gradually increased from 28.55 to $49.04 \mathrm{~nm}$. This is because the monomer conversion gradually increased as the reaction proceeded, and the core of spherical particle formed by cross-linking PTFEMA will expand with the increase of monomer conversion. Higher monomer conversion means more monomer entered into nanoreactors for polymerization resulting in larger particle size.
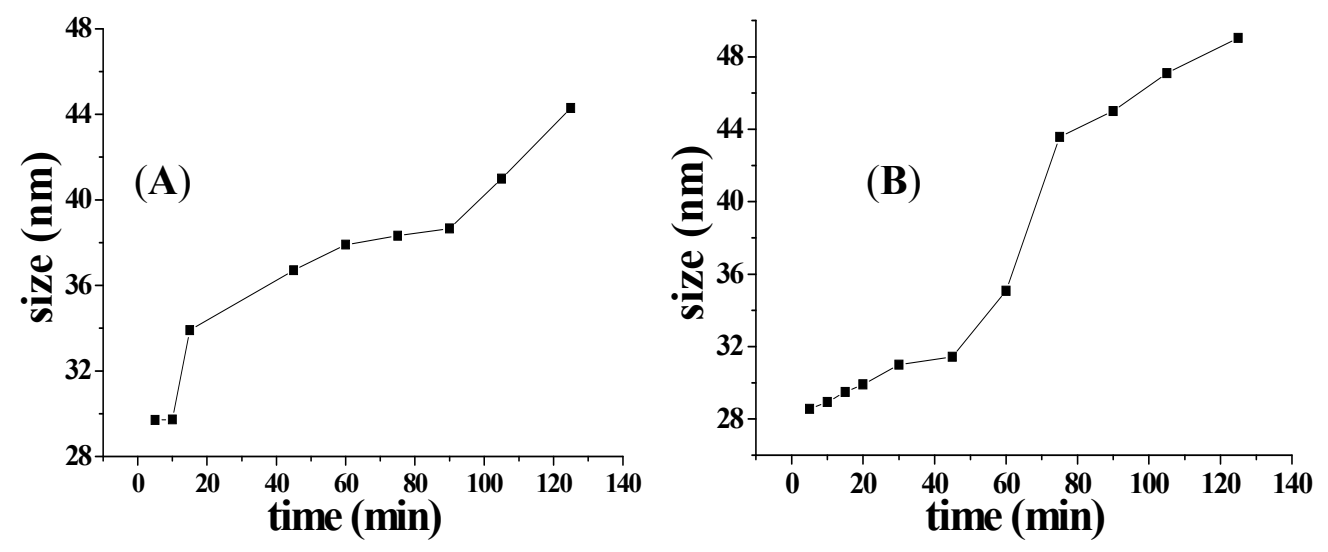

Figure 9. Cont. 


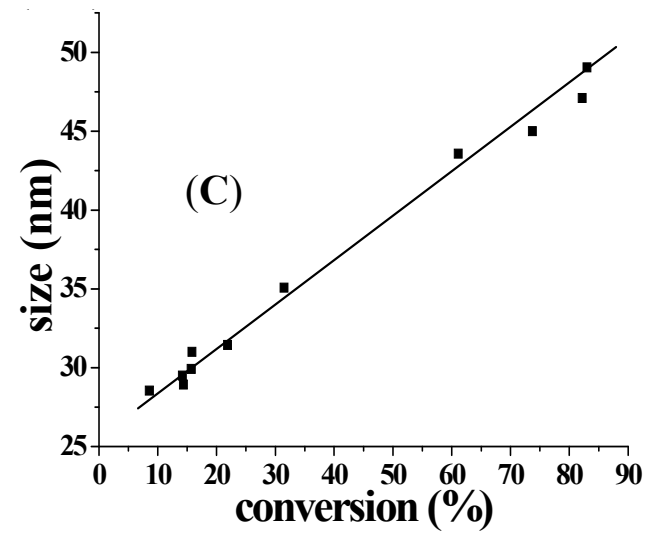

Figure 9. Evolution of particle size measured by DLS at $25^{\circ} \mathrm{C}$ versus time or conversion for RAFT-mediated aqueous polymerization. Polymerization conditions: (A) macro-RAFT agent:[TFEMA] = 1:700, macro-RAFT agent:[APS] = 9:1, [EGDMA]:[TFEMA] = 5:100, $70^{\circ} \mathrm{C} ;(\mathbf{B})$ macro-RAFT agent:[TFEMA] = 1:700, macro-RAFT agent:[APS $]=3: 1,[$ EGDMA]:[TFEMA $]=5: 100,70{ }^{\circ} \mathrm{C} ;(\mathrm{C})$ macro-RAFT agent:[TFEMA $]=1: 700$, macro-RAFT agent:[APS] $=3: 1,\left[\right.$ EGDMA] $:[$ TFEMA $]=5: 100,70{ }^{\circ} \mathrm{C}$.

\subsection{Thermo-Responsive Characterization of Cross-Linked Nanoparticles}

Figure 10A shows the effect of temperature on the particle size in the range of $14-44^{\circ} \mathrm{C}$. From 14 to $32{ }^{\circ} \mathrm{C}$ the particle diameter underwent small changes, but in the $32-37^{\circ} \mathrm{C}$ range, the particle size was dramatically reduced from 48 to $41 \mathrm{~nm}$. In the range of $35-44^{\circ} \mathrm{C}$, the particle size remained stable, indicating that the cross-linked nanospheres are temperature sensitive.

Meanwhile, it suggests that the LCST of the nanospheres is $32{ }^{\circ} \mathrm{C}$. PNIPAM segments are in a state of complete dissolution and stretching when the temperature is below $32^{\circ} \mathrm{C}$. As a result, the DLS-based size of the nanospheres is large. When the temperature is raised to the LCST of PNIPAM segments, PNIPAM segments begin to shrink rapidly leading to smaller particle size. After the complete shrinkage of PNIPAM segments at $37^{\circ} \mathrm{C}$, particle size will not change with the increase of temperature. This result proves that PNIPAM is connected with the cross-linked nanospheres, and it can freely stretch or shrink. To further prove this result, we synthesized the nanospheres with the same degree of polymerization of PDMA and PTFEMA and only changed the degree of polymerization of PNIPAM. As shown in Figure 10B, the particle size increased with the increase of degree of polymerization of PNIPAM, indicating that PNIPAM is connected with the cross-linked nanospheres outside.
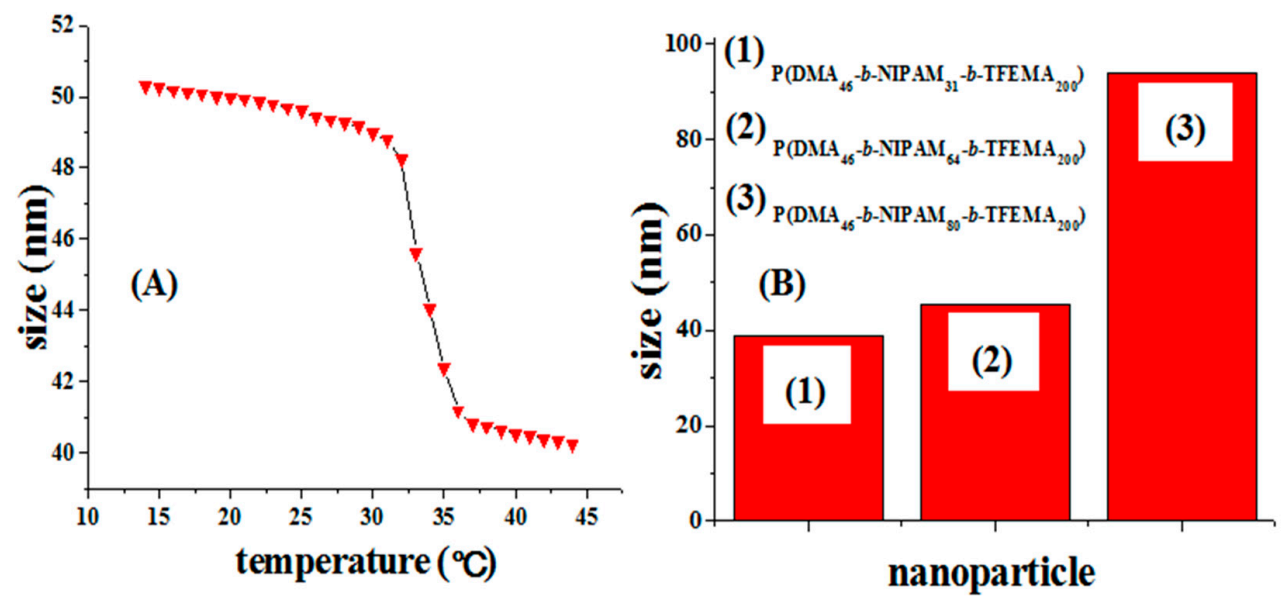

Figure 10. DLS-based size measurement of $P\left(D_{3} A_{33}-b-N_{I P A M} 163-b-T_{F E M A}\right)-S-(C=S)-S-C_{12} H_{25}$ (A) at $0.5 \mathrm{mg} / \mathrm{mL}$ concentration in water at different temperature; (B) the particle size of P(DMA- $b$ NIPAM- $b$-TFEMA)-S-(C=S)-S- $\mathrm{C}_{12} \mathrm{H}_{25}$ with different degree of polymerization of PNIPAM at $25^{\circ} \mathrm{C}$. 


\section{Materials and Methods}

\subsection{Materials and Reagents}

All reagents and solvents were of analytical grade and used as received unless otherwise stated. Ethyleneglycol dimethacrylate (EGDMA, 98\%, Aladdin, Shanghai, China) and N,N-dimethylacrylamide (DMA, 98\%, Aladdin) were passed through a column of basic alumina to remove inhibitor. N-isopropylacrylamide (NIPAM, 99\%, Sigma-Aldrich, St. Louis, MO, USA) was recrystallised from a 70:30 hexane/toluene mixture prior to use. Azobisisobutyronitrile (AIBN, Aladdin, 98\%) was recrystallized twice from methanol prior to use. (2,2,2-Trifluoroethyl) methacrylate (TFEMA) supplied by Wei Hai Newera (Weihai, China) was distilled under reduced pressure prior to use. 2-([(Dodecylsulfanyl)carbonothioyl]sulfanyl)-propanoic acid (DOPAT) was synthesized according to a literature protocol [29].

\subsection{NMR Analysis}

The ${ }^{1} \mathrm{H}-\mathrm{NMR}$ and ${ }^{19} \mathrm{~F}-\mathrm{NMR}$ analysis was performed on an AVANCE III $400 \mathrm{MHz}$ digital NMR spectrometer (Bruker BioSpin, Karlsruhe, Germany) using deuterated acetone as solvent with tetramethylsilane as the internal standard at room temperature.

\subsection{GPC Analysis}

The molecular weights and dispersity (Đ) were determined by gel permeation chromatography (GPC) at $35{ }^{\circ} \mathrm{C}$ with tetrahydrofuran (THF) as the eluent at a flow rate of $1.0 \mathrm{~mL} / \mathrm{min}$. Narrow-polydispersity polystyrene was used as calibration standard. The system was equipped with a Model 1525 HPLC pump (Waters, Milford, MA, USA) and a Waters Model 2414 refractive index (RI) detector.

\subsection{TEM Characterization}

Transmission electron microscopy (TEM) observation was performed using a JEOL-1400 electron microscope (Jeol, Tokyo, Japan). A typical TEM grid preparation was as follows: A particle solution was diluted with MilliQ water to approximately $0.10 \mathrm{wt} \%$. A formvar precoated copper TEM grid was covered with a drop of the solution for $60 \mathrm{~s}$, and counterstained with $3 \%$ uranyl acetate $(5 \mu \mathrm{L})$ for $20 \mathrm{~s}$.

\subsection{SEM Characterization}

Morphology of lyophilized particle powder analysis was conducted by scanning electron microscopy (SEM, S-2500, Hitachi Seiki, Tokyo, Japan).

\subsection{DLS Characterization}

A Zetasizer Nano-ZS90 (Malvern Instruments, Malvern, England) was used for dynamic light scattering (DLS) characterization to measure particle size (hydrodynamic diameter Z-Ave) and particle size distribution. The sample refractive index (RI) was set at 1.59 for polystyrene.

\subsection{Synthesis of Macro-RAFT Agent of PDMA $A_{77}-\mathrm{S}-(C=S)-S-C_{12} \mathrm{H}_{25}$}

In a typical synthesis, a round-bottomed flask was charged with DMA $\left(15.00 \mathrm{~g} ; 1.51 \times 10^{-1} \mathrm{~mol}\right)$, DOPAT $\left(0.5289 \mathrm{~g} ; 1.51 \times 10^{-3} \mathrm{~mol}\right), \operatorname{AIBN}\left(0.0502 \mathrm{~g}, 3.06 \times 10^{-4} \mathrm{~mol}\right.$; CTA/initiator molar ratio $\left.=4.9\right)$ and dioxane $(23.00 \mathrm{~g})$. The sealed reaction vessel was purged with nitrogen and placed in a pre-heated oil bath at $65^{\circ} \mathrm{C}$ for $7 \mathrm{~h}$. The solution was cooled in an ice bath, diluted with dioxane. The polymer was recovered by precipitation in diethyl ether, filtration and drying under vacuum for $48 \mathrm{~h}$ at $35{ }^{\circ} \mathrm{C}$. ${ }^{1} \mathrm{H}-\mathrm{NMR}$ indicated the actual degree of polymerization of 77 for the PDMA macro-CTA. $M_{\mathrm{n}}=7900 \mathrm{~g} \cdot \mathrm{mol}^{-1}$ and $M_{\mathrm{w}} / M_{\mathrm{n}}=1.12$, as determined by GPC. 


\subsection{Synthesis of Thermo-Responsive Diblock $P\left(D M A_{77}-b-N I P A M_{73}\right)-S-(C=S)-S-C_{12} H_{25}$}

In a typical synthesis, a round-bottomed flask was charged with NIPAM $\left(1.1338 \mathrm{~g}, 1.00 \times 10^{-2} \mathrm{~mol}\right)$, PDMA $_{77}$-S-(C=S)-S- $\mathrm{C}_{12} \mathrm{H}_{25}\left(1.00 \mathrm{~g} ; 1.25 \times 10^{-4} \mathrm{~mol}\right)$, AIBN $\left(0.0025 \mathrm{~g}, 1.52 \times 10^{-5} \mathrm{~mol}\right.$; CTA/initiator molar ratio $=8.2)$ and dioxane $(3.50 \mathrm{~g})$. The sealed reaction vessel was purged with nitrogen and placed in a pre-heated oil bath at $65{ }^{\circ} \mathrm{C}$ for $24 \mathrm{~h}$. The solution was cooled in an ice bath, diluted with dioxane. The polymer was recovered by precipitation in a mixture hexane:toluene $(90: 10)$, filtration and drying under vacuum for $48 \mathrm{~h}$ at $35^{\circ} \mathrm{C}$. ${ }^{1} \mathrm{H}-\mathrm{NMR}$ indicated the NIPAM actual degree of polymerization of 73 for the $\mathrm{P}\left(\mathrm{DMA}_{77}-b-\mathrm{NIPAM}_{73}\right)-\mathrm{S}-(\mathrm{C}=\mathrm{S})-\mathrm{S}-\mathrm{C}_{12} \mathrm{H}_{25} \cdot M_{\mathrm{n}}=14900 \mathrm{~g} \cdot \mathrm{mol}^{-1}$ and $M_{\mathrm{W}} / M_{\mathrm{n}}=1.15$, as determined by GPC.

\subsection{Aqueous RAFT-Mediated Polymerization of Cross-Linked TFEMA Nanoparticles in the Presence of $P(D M A-b-N I P A M)-S-(C=S)-S-C_{12} H_{25}$}

The following aqueous polymerization protocol conducted at $15 \% w / w$ solids and targeting

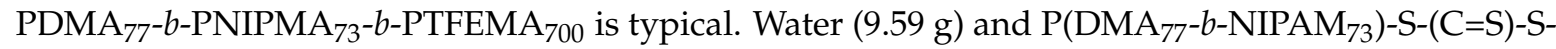
$\mathrm{C}_{12} \mathrm{H}_{25}\left(0.19 \mathrm{~g} ; 1.17 \times 10^{-5} \mathrm{~mol}\right)$ were added to a round-bottomed flask and stirred in an ice bath for $1 \mathrm{~h}$ to allow the complete solubilization of the diblocks. TFEMA (1.4179 g; $\left.8.44 \times 10^{-3} \mathrm{~mol}\right)$, EGDMA $\left(0.0833 \mathrm{~g} ; 4.21 \times 10^{-4} \mathrm{~mol}\right)$, APS $\left(0.0009 \mathrm{~g} ; 3.95 \times 10^{-6} \mathrm{~mol}\right)$ were added to the flask. The solution was deoxygenated with nitrogen and immersed in a water bath at $35^{\circ} \mathrm{C}$ for $10 \mathrm{~min}$ to allow the formation of micelles. Then the solution was heated at $70^{\circ} \mathrm{C}$ for $120 \mathrm{~min}$.

\section{Conclusions}

In summary, thermo-responsive and cross-linked PTFEMA nanospheres were successfully prepared. Firstly, RAFT solution polymerization was used to synthesize a thermo-responsive diblock copolymer $\mathrm{P}\left(\mathrm{DMA}-b\right.$-NIPAM)-S-(C=S)-S- $\mathrm{C}_{12} \mathrm{H}_{25}$ with low dispersity and well-controlled molecular weight. The ${ }^{1} \mathrm{H}-\mathrm{NMR}$ spectral analysis confirmed that copolymers were successfully synthesized. Gel permeation chromatography was conducted to demonstrate the narrow molecular weight dispersity. Then we gave evidence that the thermo-responsive diblock copolymer can turn into nanoreactors when the temperature reaches $32{ }^{\circ} \mathrm{C}$. We proceeded a successful RAFT-mediated aqueous polymerization of TFEMA using P(DMA- $b$-NIPAM)-S-(C=S)-S- $\mathrm{C}_{12} \mathrm{H}_{25}$ trithiocarbonate as both a stabilizer and a macro-RAFT agent. During the process of aqueous polymerization, the monomer conversion increased with increasing the molar ratio of initiator to chain transfer agent. The particle size increased with increasing the monomer conversion. The particle size of the cross-linked nanospheres quickly decreased when the temperature reached $32{ }^{\circ} \mathrm{C}$ showing temperature sensitivity.

Acknowledgments: Authors gratefully acknowledge the financial support from National Science Foundation of China (Grant No. 21304037) and Shandong excellent Young Scientist Research Award Fund (No. BS2013CL039).

Author Contributions: Anhou Xu, Shuxiang Zhang and Bing Geng conceived and designed the experiments; Jiachen Ma and Luqing Zhang performed the experiments and did the data analyses; Jiachen Ma and Umair Azhar wrote the paper. All authors read and approved the final version of the manuscript.

Conflicts of Interest: The authors declare no conflict of interest.

\section{References}

1. Varma, S.; McLachlan, J.; Leclair, A.M.; Galarreta, B.C.; Norton, P.R.; Lagugné-Labarthet, F. Positionally controlled growth of cells using a cytophobic fluorinated polymer. Anal. Bioanal. Chem. 2010, 396, 1159-1165. [CrossRef] [PubMed]

2. Riess, J.G. Blood substitutes and other potential biomedical applications of fluorinated colloids. J. Fluorine Chem. 2002, 114, 119-126. [CrossRef]

3. Krafift, M.P. Fluorocarbons and fluorinated amphiphiles in drug delivery and biomedical research. Adv. Drug Deliv. Rev. 2001, 47, 209-228. [CrossRef] 
4. Hansen, K.B.; Hsiao, Y.; Xu, F.; Rivera, N.; Clausen, A.; Kubryk, M.; Krska, S.; Rosner, T.; Simmons, B.; Balsells, J.; et al. Highly Efficient Asymmetric Synthesis of Sitagliptin. J. Am. Chem. Soc. 2009, 131, 8798-8804. [CrossRef] [PubMed]

5. Riess, G.; Labbe, C. Block copolymers in emulsion and dispersion polymerization. Macromol. Rapid Commun. 2004, 25, 401-435. [CrossRef]

6. Urbani, C.N.; Monteiro, M.J. Nanoreactors for Aqueous RAFT-Mediated Polymerizations. Macromolecules 2009, 42, 3884-3886. [CrossRef]

7. Hawker, C.J.; Bosman, A.W.; Harth, E. New polymer synthesis by nitroxide mediated living radical polymerizations. Chem. Rev. 2001, 101, 3661-3688. [CrossRef] [PubMed]

8. Matyjaszewski, K.; Xia, J. Atom transfer radical polymerization. Chem. Rev. 2001, 101, 2921-2990. [CrossRef] [PubMed]

9. Chiefari, J.; Chong, Y.K.; Ercole, F.; Krstina, J.; Jeffery, J.; Le, T.P.T.; Mayadunne, R.T.A.; Meijs, G.F.; Moad, C.L.; Moad, G.; et al. Living free-radical polymerization by reversible addition-fragmentation chain transfer: The RAFT process. Macromolecules 1998, 31, 5559-5562. [CrossRef]

10. Moad, G.; Chen, M.; Haussler, M.; Postma, A.; Rizzardo, E.; Thang, S.H. Functional polymers for optoelectronic applications by RAFT polymerization. Polym. Chem. 2011, 2, 492-519. [CrossRef]

11. Monteiro, M.J.; Hodgson, M.; de Brouwer, H.J. The influence of RAFT on the rates and molecular weight distributions of styrene in seeded emulsion polymerizations. Polym. Sci. Part A Polym. Chem. 2000, 38, 3864-3874. [CrossRef]

12. Brouwer, H.; Tsavalas, J.G.; Schork, F.J.; Monteiro, M.J. Living radical polymerization in miniemulsion using reversible addition-fragmentation chain transfer. Macromolecules 2000, 33, 9239-9246. [CrossRef]

13. Ferguson, C.J.; Hughes, R.J.; Pham, B.T.T.; Hawkett, B.S.; Gilbert, R.G.; Serelis, A.K.; Such, C.H. Effective ab initio emulsion polymerization under RAFT Control. Macromolecules 2002, 35, 9243-9245. [CrossRef]

14. Stoffelbach, F.; Tibiletti, L.; Rieger, J.; Charleux, B. Surfactant-free, controlled/living radical emulsion polymerization in batch conditions using a low molar mass, surface-active reversible addition-fragmentation chain-transfer (RAFT) agent. Macromolecules 2008, 41, 7850-7856. [CrossRef]

15. Zetterlund, P.B.; Kagawa, Y.; Okubo, M. Controlled/living radical polymerization in dispersed systems. Chem. Rev. 2008, 108, 3747-3794. [CrossRef] [PubMed]

16. Pepels, M.P.F.; Holdsworth, C.I.; Pascual, S.; Monteiro, M.J. RAFT-mediated emulsion polymerization of styrene with low reactive xanthate agents: Microemulsion-like behavior. Macromolecules 2010, 43, 7565-7576. [CrossRef]

17. Schönfelder, D.; Fischer, K.; Schmidt, M.; Nuyken, O.; Weberskirch, R. Poly(2-oxazoline) functionalized with palladium carbene complexes: Soluble, amphiphilic polymer supports for $\mathrm{C}-\mathrm{C}$ coupling reactions in water. Macromolecules 2005, 38, 254-262. [CrossRef]

18. Schönfelder, D.; Nuyken, O.; Weberskirch, R.J. Heck and Suzuki coupling reactions in water using poly(2-oxazoline)s functionalized with palladium carbene complexes as soluble, amphiphilic polymer supports. Organomet. Chem. 2005, 690, 4648-4655. [CrossRef]

19. Schild, H.G. Poly(N-isopropylacrylamide): Experiment, theory and application. Prog. Polym Sci. 1992, 17, 163-249. [CrossRef]

20. Garnier, S.; Laschewsky, A. New amphiphilic diblock copolymers: Surfactant properties and solubilization in their micelles. Langmuir 2006, 22, 4044-4053. [CrossRef] [PubMed]

21. Save, M.; Manguian, M.; Chassenieux, C.; Charleux, B. Synthesis by RAFT of amphiphilic block and comblike cationic copolymers and their use in emulsion polymerization for the electrosteric stabilization of latexes. Macromolecules 2005, 38, 280-289. [CrossRef]

22. Rieger, J.; Stoffelbach, F.; Bui, C.; Alaimo, D.; Jérôme, C.; Charleux, B. Amphiphilic poly(ethylene oxide) macromolecular RAFT agent as a stabilizer and control agent in ab initio batch emulsion polymerization. Macromolecules 2008, 41, 4065-4068. [CrossRef]

23. Ganeva, D.E.; Sprong, E.; Bruyn, H.D.; Warr, G.G.; Such, C.H.; Hawkett, B.S. Particle formation in ab initio RAFT mediated emulsion polymerization systems. Macromolecules 2007, 40, 6181-6189. [CrossRef]

24. Winnik, F.M. Fluorescence studies of aqueous solutions of poly( $N$-isopropylacrylamide) below and above their LCST. Macromolecules 1990, 23, 233-242. [CrossRef]

25. Valade, D.; Jeon, Y.; Kessel, S.; Monteiro, M.J. Influence of the Z-group on the RAFT-mediated polymerizations in nanoreactors. Polym. Sci. Part A Polym. Chem. 2012, 50, 4762-4771. [CrossRef] 
26. Gupta, M.K.; Martin, J.R.; Werfel, T.A.; Shen, T.W.; Page, J.M.; Duvall, C.L. Cell Protective, ABC Triblock Polymer-Based Thermoresponsive Hydrogels with ROS-Triggered Degradation and Drug Release. J. Am. Chem. Soc. 2014, 136, 14896-14902. [CrossRef] [PubMed]

27. Yang, B.Q.; Duhamel, J. Extraction of Oil from Oil Sands Using Thermoresponsive Polymeric Surfactants. ACS Appl. Mater. Interfaces 2015, 7, 5879-5889. [CrossRef] [PubMed]

28. Zhou, J.H.; Wang, H.L.; Zhang, L.; Ma, J.Z. Ab initio reversible addition-fragmentation chain transfer emulsion polymerization of styrene/butyl acrylate mediated by poly(acrylic acid)-block-polystyrene trithiocarbonate. Polym Int. 2014, 63, 2098-2104. [CrossRef]

29. Zhou, Y.X. Synthesis of three trithiocarbonates reversible addition-fragmentation chain transfer agents by phase transfer catalysis reaction. Contemp. Chem. Ind. 2013, 42, 152-155.

Sample Availability: Samples of the compounds are available from the authors.

(C) 2017 by the authors; licensee MDPI, Basel, Switzerland. This article is an open access article distributed under the terms and conditions of the Creative Commons Attribution (CC-BY) license (http:/ / creativecommons.org/licenses/by/4.0/). 